\title{
Design and Research of Campus E-commerce System Based on $\mathrm{B} / \mathrm{S}$
}

\author{
Jinhuan Wang \\ Intelligent Science \& Information Engineering College, Xi'an \\ Peihua University \\ Xi'an 710125, China
}

\begin{abstract}
Internet life has become an indispensable part of people, and the e-commerce model has greatly changed the way people live their lives. However, the application of e-commerce in the campus field is not enough. Aiming at current problems and actual needs of the campus, this paper proposes the design and research of campus e-commerce system based on $B / S$ (Browser/Server), to realize the second-hand commodity transaction in campus. The system adopts $\mathrm{B} / \mathrm{S}$ structure, and its function design mainly includes: station news, product display, commodity trading, member registration, contact us, background management, etc. The implementation of this system can bring convenience to students' life and study, it also can realize the benign circulation of second-hand commodity in campus.
\end{abstract}

\section{Keywords-e-commerce; $B / S ;$ transaction platform}

\section{INTRODUCTION}

Since the rise of the Internet, business opportunities relying on the Internet have been continuously mined. The way of Internet trading has opened up a new world for people and become an inevitable way in the development of e-commerce. The original intention of designing this system was to solve the problem that traders could not meet their own needs in time. At present, in addition to large-scale e-commerce platforms such as Taobao and Jingdong, the online platform based on campus has gradually developed within the school. Each consumer can post the items they want to trade to the website in the form of basic information. Other students log in the webpage to view the latest campus old things transaction items published by other consumers in real time. After submitting the order, you can contact the seller to pay, which enables convenient real-time online transactions. The development of this website saves the unnecessary costs of store affected by the unpredictable factors such as environment, location and time. At the same time, it meets the needs of students for timely consumption, realizing the dual needs of facilitating both consumers and sellers, and saves time for buyers and sellers, which has considerable practical significance. It is especially important to establish a cross-border trading platform. The website will provide users with more diverse, richer and more personalized services.

\author{
Yan Li \\ Intelligent Science \& Information Engineering College, Xi'an \\ Peihua University \\ Xi'an 710125, China
}

\section{SYSTEM ANALYSIS}

\section{A. System design object}

According to the characteristics of the university, this study makes full use of the characteristics of the campus and builds a campus-based cross-border trading platform, to realizes online trading system's member login and registration, product display, purchase, transaction and post-related background management functions. This platform adopts J2EE technology and mysql database, to analyze the system and thinks how to save time and effort to the greatest extent from the perspective of users, thereby achieving a standardized, networked, information-based, and systematic platform with better applicability and promotion. This system includes two parts: foreground management and background management. The foreground is a simple and generous operation interface for users to browse and query, including: products browser, commodity transactions, transaction information release, message board, contact sellers, products uploading, etc. Background management is provided to administrators, including: commodity management, user management, and order management, ect.

\section{B. Overview of system function requirements}

The system is mainly based on commodities, taking the campus network as a platform and the university's teachers and students as the subjects. It provides them with a campus e-commerce platform for publishing and buying and selling second-hand items. We see that there are a lot of recyclables in college, especially in the senior year of graduation. Often due to the occlusion of the sale of recyclables and the limitations of traditional information trading methods, a large part of items with certain value are wasted, and even are treated as rubbish. Now, as long as you enter the platform through the campus network, you can publish and sell goods conveniently and quickly, and you can also communicate with the seller by the way of leaving messages. Since each university's campus network basically covered every part of the campus, as long as it is properly promoted, in theory, everyone can let the whole school know the information published, and strive to maximize the use of information resources.

This website allows the members login to mainly achieved user setting functions, information publishing functions, information management functions, information searching 
functions, message functions, and system management functions. With comprehensive capabilities of high-speed mobile, big data analysis and mining, intelligent sensing and applications, it can penetrate into traditional industries to enhance the service capabilities of traditional industries, and connect hundreds of industries to conduct online and offline cross-border marketing.

The system function structure diagram is shown in Figure 1:

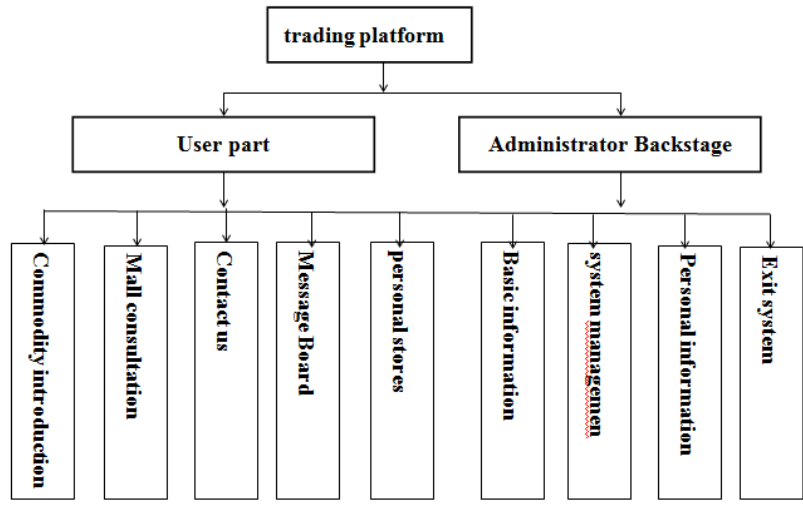

Fig. 1 Diagram of system function structure

\section{SYSTEM DESIGN}

\section{A. System architecture design}

The system adopts the B/S mode architecture. Our system uses application programs to develop three phases of the $\mathrm{B} / \mathrm{S}$ structure. At present, the Internet application architecture, transaction processing is divided into three levels, namely Web browser, Internet server, database server. In this architecture, business performance is easy to implement through the web browser, and when the user submits the form through the web browser, the information is provided to the Internet server for consumer demand. The Internet server performs the required analysis query, the database server executes, and then the database server's query results are returned to the web browser using the standard HTML language.

\section{B. System flow chart design}

When the user logs in to the system, the system compares the account and password registered by the user with the data in the database. If the account and password are both correct, the user can log in to the system and perform some personal information management information processing. The buyers and sellers designed the function of message information when designing the system, so that the user can contact the seller well, so as to provide guarantee for the later transaction and the flow chart design of the message information.

\section{Database structure design}

\section{1) Database conceptual model}

The most widely used database today is a relational database. Because it is an object-oriented system design, it's definitely that the design of the database must face objects. Now what should be considered about the persistent operation of the object class, that is, how the object class is mapped to the two-dimensional table of the relational database. Nowadays, like Power Designer, Rose, etc. all can be achieved by using database modeling tools.

Database concept design's overall attribute E-R diagram, as shown in Figure 2:

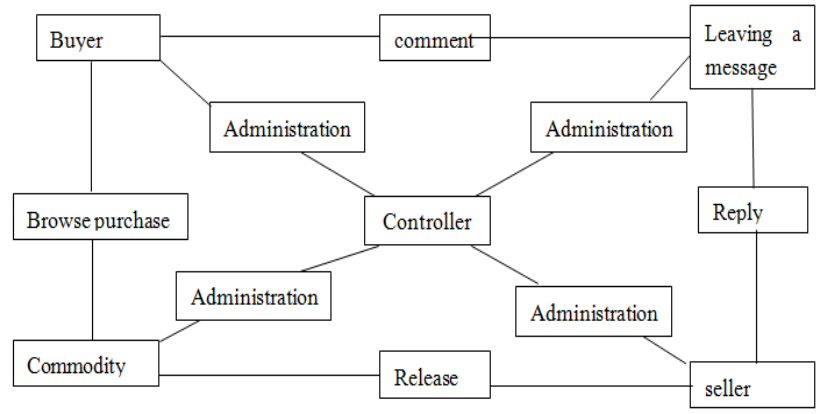

Fig. 2 Diagram of overall attribute E-R

The diagram shows that a rectangular template represents an entity. The relationship of the entity of the subsequent parts is represented by a diamond. The undirected line is a tool connecting the "diamond" with the "related entity", and the type of the connection is indicated on the side as needed. The attributes of the entity are represented by an ellipse that can be used according to the template, and are later omitted in the diagram according to the situation.

\section{2) Partial database data table field design}

In the stage of designing physical structure, first take two steps: First, determine the physical structure of the database in the relational database, mainly referring to the access method and the storage structure. Time and space efficiency is an evaluation of the physical structure. Then select the access method, and it is the correct relation mode. Access index method, cluster access, HASH access method, etc. are all common methods.

According to the above specification, the partial table of the database is designed as follows: 
a) Publication Messages Table

TABLE I Publication Messages Table

\begin{tabular}{|c|c|c|c|c|c|}
\hline Serial number & Field name & Field type & $\begin{array}{l}\text { Allowed to be } \\
\text { empty }\end{array}$ & Maximum length & Remarks \\
\hline 1 & Id & int & Self increment & 11 & number \\
\hline 2 & saver & varchar & yes & 255 & User name \\
\hline 3 & savetime & varchar & yes & 255 & Publication time \\
\hline 4 & content & varchar & yes & 255 & Publish content \\
\hline 5 & recontent & varchar & yes & 255 & Administrator replies \\
\hline
\end{tabular}

b) Mall News Table

TABLE II MALl News TABLE

\begin{tabular}{|c|c|c|c|c|c|}
\hline Serial number & Field name & Field type & Allowed to be empty & Maximum length & Remarks \\
\hline 1 & Id & Int & Self increment & 11 & number \\
\hline 2 & Title & Varchar & yes & 255 & News headlines \\
\hline 3 & Content & Text & yes & 255 & News content \\
\hline 4 & Savatime & Varchar & yes & 255 & Release time \\
\hline 5 & Infotype & Varchar & yes & 255 & classification \\
\hline
\end{tabular}

c) Sysuser table

TABLE III SYSUSER TABLE

\begin{tabular}{|c|c|c|c|c|c|}
\hline Serial number & Field name & Field type & Allowed to be empty & Maximum length & Remarks \\
\hline 1 & Id & Int & Self increment & 11 & number \\
\hline 3 & Upass & Varchar & yes & 255 & User password \\
\hline 4 & Utype & Varchar & yes & 255 & User identity \\
\hline 5 & Tname & Varchar & yes & 255 & Full name \\
\hline 6 & Sex & Varchar & yes & 255 & Gender \\
\hline 7 & Age & Varchar & yes & 255 & Age \\
\hline 8 & Tel & Varchar & yes & 255 & Telephone \\
\hline 9 & Addrs & Varchar & yes & 255 & address \\
\hline 10 & Filename & Varchar & yes & 255 & Head photo \\
\hline 11 & $\mathrm{Qq}$ & Varchar & yes & 255 & QQ \\
\hline 12 & Bei & Varchar & yes & 4000 & Remarks \\
\hline
\end{tabular}

d) Commodity List Published

TABLE IV COMMOdITY List PUBLISHED

\begin{tabular}{|c|c|c|c|c|c|}
\hline Serial number & Field name & Field type & Allowed to be empty & Maximum length & Remarks \\
\hline 1 & Id & Int & Self increment & 11 & number \\
\hline 3 & Proname & Varchar & yes & 255 & Trade name \\
\hline 4 & Price & Varchar & yes & 255 & commodity price \\
\hline 5 & Discount & Varchar & yes & 255 & Quantity of commodities \\
\hline 6 & Filename & Varchar & yes & 255 & Commodity pictures \\
\hline 7 & Bei & Varchar & yes & 4000 & Commodity notes \\
\hline
\end{tabular}




\begin{tabular}{llll}
\hline 8 & Btype & Varchar & Table IV \\
9 & Stype & Varchar \\
10 & Status & Varchar \\
11 & Savetime & Varchar \\
12 & Cjnum & Varchar \\
13 & fz & varchar \\
\hline & IV. SYSTEM IMPLEMENTATION
\end{tabular}

The server-side program uses the Spring MVC framework to access the database.

\section{A. Implementation of system login module}

The step of user login, first, save the information input by the user, and then use the program to retrieve from the database to see if the information input by the user exists in the database. If yes, it returns the correct result, and if not, it returns the wrong result. If the database exists the information, it shows login successful, otherwise shows login fail. Please $\log$ in again.

\section{B. Design of student foreground module}

The student's login allows students to quickly find the system functions they need. The system sets a system guide at the top of the home page: After the user successfully registers and inputs his user name and password, he enters the home page. The system calls the SQL statement to query the basic information in the user table S-user and displays it on the page. If the registered user wants to modify his own information, he can modify the current role data in the seller center. The navigation bar allows users to quickly find the system functions they need.

Mall module design: The mall introduction is the Internet community uploaded by the administrator and the relevant information about the mall in our vicinity. After the administrator uploads in the background, the buyer can browse the relevant information at the foreground. Message board function module design: Message board is also one of the essential design functions of many websites, it can effectively communicate the contact between buyers and sellers. On the other hand, the comments made by the purchased buyers can also be used for reference and referenced by later people, but uncivilized comments will be deleted by the system administrator.

\begin{tabular}{lll} 
yes & 255 & $\begin{array}{l}\text { Primary Classification of } \\
\text { Commodities }\end{array}$ \\
yes & 255 & $\begin{array}{l}\text { Secondary Classification of } \\
\text { Commodities }\end{array}$ \\
yes & 255 & Commodity status \\
yes & 255 & Upload time \\
yes & 255 & Surplus stock \\
yes & 1255 & Commodity introduction \\
\hline C. & Design of background management module
\end{tabular}

After the administrator login interface, the system background menu is divided into: website information, basic information, system management and personal management. Basic information management is a basic related operation for adding, modifying, and deleting seller members, product information, product evaluation, and product attributes. The deletion management of uncivilized comments can purify the content of platform comments. System management is an administrator system function designed to better realize the informationization and standardization of the platform. Super administrators can add other administrators to assist them in the management work.

\section{CONCLUSIONS}

This paper proposes the design of a second-hand commodity trading system based on the $\mathrm{B} / \mathrm{S}$ architecture aiming at problems existing in the campus. The system function design mainly realizes the station news, product display, commodity trading, member registration, contact us, background management and so on. The campus trading system has great practical value in reality, which not only reduces the learning cost of students, but also reuses learning resources.

\section{ACKNOWLEDGMENT}

This work was supported by the thirteenth Five-Year Plan" for Education Science in Shaanxi Province in 2018 No. SGH18H509 and Special research project of Shanxi Provincial Department of Education in 2018. No.18JK1084.

\section{REFERENCES}

[1] Wang Ying. Design and Implementation of Student Status Information Management System Based on JSP[J]. University of Electronic Science and Technology of China, 2012.

[2] Zhu Liping. Development and Implementation of University Library Management System Based on JSP[J]. University of Electronic Science and Technology of China, 2011.

[3] Lv Yong. Design and Implementation of Laboratory Project Management System Based on JSP[J]. Wuhan University of Technology, 2012.

[4] Beecham, Matthew.Global market review of front-end modules for passenger cars and light trucks - forecasts to 2017: 2010 edition: Appendix 2 Q\&A with JSP[J].Just - Auto, 2010, pp.32-35. 